\title{
Research on the Development Trend of Visual Communication Design Education in the Cultural and Creative Industries
}

\author{
Bing Liu \\ Academy of Fine Arts \\ Northeast Normal University \\ Changchun, 130024 \\ ice8515@163.com
}

\author{
$\mathrm{Fu} \mathrm{Liu} *$ \\ Academy of Fine Arts \\ Northeast Normal University \\ Changchun, 130024 \\ fuliu6286@163.com
}

\begin{abstract}
From the theoretical evolution and practical development, the theoretical framework, development status and characteristics of the teaching reform of visual communication design are studied. The results shows, cultural and creative industries are the important factors that affect the development of visual communication design education, in order to meet the needs of modern society for visual communication design talents, need to change the teaching concept, and reform the curriculum, teaching methods and personnel training mode, emphasis on "experiment" and "practical". This research provides a full range of theoretical guidance and practical path for the educational development of visual communication design.
\end{abstract}

Keywords-visual communication design; cultural and creative industries; educational development trend; research methodology

\section{INTRODUCTION}

With the rapid development and transformation of the global economy and industry, "cultural and creative industries" not only bring about the changes in the form and pattern of culture, but also lead to the commercialization and consumption of culture, its development scale and level have become an important symbol to measure the level of comprehensive competitiveness of a country [1,2]. Visual communication design is an important part of cultural and creative industries, meaning and nature are also changing quietly, from the traditional arts and crafts, decoration, decoration and gradually develop, the formation of a more inclusive and rich content of the new category of subjects, extends to film and television, animation, advertising, video news, digital, network, games and other emerging areas [3-5].

In essence, visual communication design is a kind of cultural practice mode relying on the modern high technology and media, has become an important support force for the development and selection of creative industries. The development of cultural and creative industries put forward higher request to the modern art design education. Design education should be more open and inclusive, in the teaching mode, actively explore and break the normal procedure, for the development of cultural and creative industries, to cultivate the creative awareness of the information technology talents [6, 7].

\section{ANALYSIS AND PRACTICE OF RESEARCH CONTENTS}

The idea of visual communication design and the rise of subjects, is accompanied by the development of commercial economy, media technology innovation and progress, as well as social science, communication, semiotics and psychology and so on, it is a new emerging discipline, with a variety of professional division, have comprehensive and common characteristics.

Diversified visual art concept, reveals a new way of visual communication, breaking the limits of traditional design categories, let visual communication design become a kind of subject carrier, it is free to merge with other disciplines, highlight the comprehensive, cross disciplinary background, in the development of visual culture and creative culture industry, has important significance and value. The appearance and popularization of visual communication design, challenge the form of contemporary art design, enrich the extension of contemporary art and design, and to determine the division of traditional art design layout, showing the unique form and connotation, expand the application field and category of traditional art design.

Visual communication innovation design education is based on the form, aesthetic and expressive ability, the overall promotion of creative thinking and comprehensive quality, it is the study of visual and symbolic communication environment as the main body, and the comprehensive practice and exploration of visual language. We need to liberate the design education from the creative thinking training in the form of innovation, research on the education and training method of creative talent.

\section{A. Deepen the Understanding of Art and Creative Industries.}

Deepen the understanding of art and creative industries, need to sort out the theoretical framework of the development of creative industries, the analysis of the history of the creation of the creative industries of objectivity and inevitability, and analysis of the nature of the art and creative industries and functional role. The author put forward a more comprehensive definition of the concept and category of creative industries, to 
deepen understanding of the essence on the art of creative industry, understanding of the necessity and urgency on development, this study has an important significance for the development of creative industries.

At present, from the perspective of economics, the research of art creative industry is still relatively lacking, analysis of the creative industries of the external, public goods and value chain, etc., to explore the new path of art creative industry from the perspective of economics, which has a certain theoretical significance to the study of the development of creative industries.

\section{B. Provide Basis in Order to Improve the Policy System of the Development of Art Creative Industry}

A comprehensive review of the present situation of the development of art creative industry from the aspects of the development stage and the achievement, based on the industry itself, the market environment, government support and other perspectives, a profound analysis of the existing problems in the art and creative industries, based on the industry itself, the market environment, government support and other perspectives, a profound analysis of the existing problems in the art and creative industries, analyze and compare the development practice and successful experience of art creative industry in the world, to provide reference for the legislation, planning, management system, intellectual property protection, personnel training and other public policies of art and creative industries. This study is conducive to accelerate the development of China's cultural and creative industries; to promote the "internationalization" of Chinese art has a positive significance.

\section{Put Forward a New Thinking for the Development of Visual Communication Design Subject and Visual Culture Creative Industry}

Professional colleges and universities in the education of visual communication design, not only to explore the teaching methods, but also to change the teaching concept, the combination of visual communication design teaching and cultural industry market. Industry market is an important measure to test the success of instructional design; emphasis on "experiment" and "practical" should be the focus of the teaching of visual communication design. Instill cultural and creative industries in the school; it is beneficial to cultivate students' sense of competition and the ability of social adaptation. Effectively will be the traditional teaching classroom, from the plane of the three-dimensional teaching mode, pay more attention to the teaching process of market practice, make visual communication design teaching more perfect, for the development of cultural and creative industries continue to inject new vitality, to cultivate comprehensive talents with innovative ability.

\section{VALUE AND SIGNIFICANCE OF RESEARCH}

Art design can extend the value chain of cultural and creative industries, through the development of derivative products, the industry chain has been expanded and extended, on the one hand derived products rely on native creativity, on the other hand, the production of derivatives, creative product sales also need to be creative, art creative design is conducive to the formation of the industrial agglomeration effect. Art design to guide the cultural and creative industries of the industrial trend, has the characteristics of virtual, advanced, unique and fashion, this allows the creation of virtual creative products by artistic design, can guide people's consumption trend, once consumers have recognized the product, it is a kind of high grade; the new brand products are popular in the market, to guide the development of all industries including cultural and creative industries, including the trend. Art design can achieve the symbol of goods, differentiation, diversification, with the development of symbol consumption, fashion consumption and differentiated consumption, art design will guide the development of cultural and creative industries.

\section{A. Research of the Definition on Art Creative Industry and Its Role in Economic and Social Development}

Definition and classification of cultural and creative industries are analyzed, from the cultural industries, creative industries, cultural and creative industries to gradually transform the evolution of ideas and perspectives; an analysis of the characteristics and laws of the development of artistic creative industries, from the creativity oriented, talent oriented, high income and high risk, the protection of intellectual property rights and anti economic depression characteristics and other aspects. This paper expounds the main functions and important functions of the development of artistic creative industries, from the economic, cultural, social and ideological functions of art and creative industries.

The idea of visual communication design and the way of thinking, there has been a fundamental shift, that is, from the traditional graphic design based expression, developed into a multi angle and full range of visual language. From the performance practices, by the previous emphasis on the performance of the art form, development to now begin to pay attention to business marketing, pay attention to the design and expression of consumer psychology and product personality; in the scope of design and communication form, from the original single several media, development to today's comprehensive and diversified media era, visual language extends from "static" to "dynamic", from the plane to the "three dimensional" development to the "four-dimensional" space.

\section{B. Research of the Development Stage, Current Situation and Existing Problems of Art Creative Industry}

The creative product of contemporary visual communication design has the characteristics of science and technology, in particular, high-tech, such as the rapid development of IT industry, laid the scientific foundation and technical support for the development of visual communication design. The new era makes the design idea and the making method, great changes have taken place in both connotation and form, at the same time, modern design has absorbed the excellent research results of modern science and technology, in the past simple and backward mode of transmission and means, to form a design product with the characteristics of the times and innovative consciousness. 
The theoretical framework, development status and characteristics of the formation of creative industries in the arts are studied, around the industry itself, the market environment and government support, the problems and deficiencies in the art creative industry are analyzed, discuss the economic theory of supporting and promoting the development of creative industry.

\section{Reflection on the Influence of the Teaching Reform of Visual Communication Design from the Cultural and Creative Industries}

The essence of visual language research is to put the visual communication design into a more scientific and reasonable curriculum teaching system, based on the teaching and practice of visual sign language, visual language reality and historical environment, highlight the visual communication design visual innovation, communication art and scientific characteristics; make teaching close to the market and the development of visual culture, the concept of innovative design into the teaching content and various links, complete the transformation from the traditional formalism aesthetics to the visual culture creation idea.

Cultural and creative industries provide a broad space for the future of visual communication design, visual communication education is the most important way to cultivate creative talents, and they are complementary to each other. In order to meet the new requirements of the new era, from the establishment of training objectives, the establishment of professional courses, the reform of teaching methods, the construction of the practice base, as well as the teaching of the second classroom and even the deployment of faculty, they all need break the traditional teaching mode of visual communication design, exploring the direction of visual art teaching reform, so as to improve the teaching quality.

\section{FEASIBILITY STUDY AND MULTI-OBJECTIVE ANALYSIS RESEARCH}

\section{A. News Analysis: The Concept and Classification of Artistic Creativity Industry.}

Drawing lessons from domestic and foreign scholars on the research experience of art creative industry, the development and practice of China's art creative industry is studied. New definition of art and creative industries design concept, highlighting the humanities, creative, high-end and other elements; scientific definition of the scope of the creative arts industry, laid the theoretical foundation for the development of cultural and creative industries policy.

Research focuses: on the transformation of the traditional art industry to the modern art and creative industries; the impact of the emerging art creative industries on the surrounding industries and the economy; combined with the development of China's artistic creative industries, from the industrial scale, cultural environment, science and technology research, human resources, consumer groups and capital investment and other aspects of the art creative industry development index to sort out.

\section{B. To Sum Up the Experience and Lessons of Art Creative Industry, and Strategically Improving Proposals are Put Forward.}

In the creative economy and the cultural industry to flourish today, visual communication design is faced with great opportunities for development, new society represented by digital civilization, it is urgent to innovate the concept of art design.

People hope the visual communication design to obtain the unprecedented development of new spirit, new art, new tools, new space, new media, to show the magic of the scene, meet the needs of all aspects. For designers, the diversified development of the cultural field of vision and the knowledge structure is an irreversible reality, this will also make the whole creative industry has a more broad space for development.

\section{Reflections on the Development of Visual Communication Design and the Creative Industries of Visual Culture}

Culture is the soul of the development of visual communication design creative products. Cultural industry is the capital of cultural resources, market demand as the guide, through the use of cultural creativity and artistic wisdom, and ultimately to cultural products and services to the community, and to win economic and social benefits. Chinese history and culture is extensive and profound, the folk culture has a long history, the red cultural characteristic is bright, and the modern culture is rich and colorful. We develop visual communication design to rely on the excellent culture of the Chinese nation, giving the traditional culture with a new soul, so that the real meaning of traditional culture to obtain vitality, it is the important research topic of today's visual communication design.

Science and technology is the support of the development of creative industries in visual communication design. Visual communication design creative product is the product of technological civilization. The development of creative industries, we must closely rely on science and technology. The rapid development of science and technology has brought great impetus to the development of visual communication design. From the invention of photography, film and television, to the emergence of computer multimedia, with the continuous innovation of communication technology, the fields of visual communication design and the way of expression has been expanding. We want to speed up the application of digital, network and other modern information technology in the creation, production, communication and other aspects of art products, Strengthen the development of visual communication design content products.

\section{CONCLUSION}

Visual communication design education must pay close attention to market trends, explore the social culture and industry services, emphasis on "experiment" and "practical", instill cultural and creative industries in the school, it is beneficial to cultivate students' sense of competition and the ability of social adaptation. Effectively will be the traditional teaching classroom, from the plane of the three-dimensional teaching mode, pay more attention to the teaching process of 
market practice, make visual communication design teaching more perfect, for the development of cultural and creative industries continue to inject new vitality, to cultivate comprehensive talents with innovative ability.

China is in the stage of vigorous development of cultural and creative industries; the art, film and television industry, which is covered by the cultural and creative industries, is closely related to the visual communication design. Visual communication design education as a cultural and creative industry chain of an intermediate link, undertake the task of training innovative, open and applied talents; especially in the context of cultural and creative industries, the development of visual communication design needs to be combined with the actual needs of local social and economic development, innovative exploration and in-depth study of professional teaching, to provide creative sources and high-quality creative talents for the future development of cultural and creative industries, in order to promote social progress and economic development, to achieve a win-win situation in colleges and universities and personnel training.

\section{CORRESPONDING AUTHOR}

$\mathrm{Fu}$ Liu, Northeast Normal University, CHINA. fuliu6286@163.com.

\section{ACKNOWLEDGMENT}

The authors gratefully thanks the financial support by Jilin Social Science Fund Project (2013BS14), Jilin Province "12th
Five-year Plan" Education and Science Fund Project (GH150007), Youth fund of Northeast Normal University in philosophy and social science school projects (13QN028), Youth fund of Northeast Normal University in philosophy and social science school projects - Art project (MSZX2012-01).

\section{REFERENCES}

[1] Jesvin PuayHwa Yeo, "An overview of research methods in visual communication design education," International Journal Of Design Creativity And Innovation, vol. 2(1), 2013, pp. 51-62.

[2] GM Mejía, S Chu, "A Model for Visual Communication Design: Connecting Theories of Rhetoric, Literacy and Design," Design Journal, vol. 17(1), 2014, pp. 29-43.

[3] Luciana Lazzeretti, Francesco Capone, I. Erdem Seçilmiş, "In search of a Mediterranean creativity. Cultural and creative industries in Italy," Spain and Turkey, European Planning Studies, vol. 24(3), 2015, pp. 568588.

[4] Andrew White, Sujing Xu, "A critique of China's cultural policy and the development of its cultural and creative industries: the case of Shanghai," Cultural Trends, vol. 21, 2012, pp. 249-257.

[5] Susan Galloway, Stewart Dunlop, “A Critique of Definitions of the Cultural and Creative Industries in Public Policy," International Journal of Cultural Policy, vol. 13, 2007, pp. 17-31.

[6] Audrey Yue, "Cultural governance and creative industries in Singapore," International Journal of Cultural Policy, vol. 12, 2006, pp. 17-33.

[7] Toby Miller, "From Creative to Cultural Industries: Not all industries are cultural, and no industries are creative," Cultural Studies, vol. 23, 2009, pp. 88-99. 